\title{
A new beginning for the Hong Kong Journal of Ophthalmology, the official journal of the College of Ophthalmologists of Hong Kong
}

As the new Editor-in-Chief of the Hong Kong Journal of Ophthalmology (HKJO), it is my great pleasure and honor to have the opportunity to work with the distinguished Editorial Board and to continue to provide the College and our Fellows with a first-class publication. Owing to the invaluable achievements of my predecessors and colleagues, articles of HKJO are already easily accessible and retrievable through Google Scholar. One of the missions of the Editorial Board is to advance the scientific standard and reputation of our Journal. We would like to promote our Journal to regional and international scholars, and having the Journal included a citation index is an important step on the path to our future success. We have been working hard to prepare our Journal to be included in PubMed Central, subject to vigorous evaluation standards. ${ }^{1}$ The following actions have been undertaken: (1) current National Library of Medicine policies for PubMed Central inclusion have been reviewed; (2) current standards and best practices for scholarly journals have been discussed with the publisher (HKAM Press; https://www.hkampress.org/) and areas for improvement have been identified; (3) the Journal's online submission platform has been updated to the latest version, to ensure future seamless integration to PubMed Central and compliance with the latest publication standards; and (4) an improved plagiarism detection service (iThenticate; http://www.ithenticate.com/) has been subscribed to. Actions in progress include (1) updating the author guidelines and submission processes to meet the latest standards of the International Committee of Medical Journal Editors, ${ }^{2}$ (2) applying for inclusion of HKJO in the Directory of Open Access Journals (DOAJ; https://doaj.org/) as a quality test, and (3) planning to collect at least 25 new articles for submission to PubMed Central for quality assessment. A crucial pre-requisite for inclusion in PubMed Central is the regular publication of quality peer-reviewed articles.
We would like to take this opportunity to solicit your kind support to help HKJO getting indexed.

In this issue, we have two informative original articles. Lau et $\mathrm{al}^{3}$ share with us on the safety and efficacy of atropine treatment in a private hospital in Hong Kong for slowing myopia progression in children in a 5-year review. Wong et $\mathrm{al}^{4}$ reviewed cases of retinoblastoma in a tertiary referral public hospital in Hong Kong from 2008-2019, highlighting the incidence, clinical features, and outcomes of this importance disease. Multiple-choice questions related to the above two articles have been designed to provide CME credits for Fellows of the Hong Kong Academy of Medicine. It is the first time that Fellows can complete the CME questions online at https://www.icmecpd.hk/ for immediate credit of the points. We strongly encourage our Fellows to use the above electronic method, as the old hard copy method will not be provided in future issues.

I warmly thank all of our valued readers, College Fellows, and the Editorial Board, and especially our Associate Editor, Dr Alvin Au Ka Hong, for all of the precious contributions to $\mathrm{HKJO}$ in the past and coming years.

\section{Alvin KH Kwok}

$M D(H K), M D(C U H K), P h D(H K), F R C S(U K)$, FRCOphth

(UK), FHKAM (Ophth), PostGrad DipEpidem \& Biostat

(CUHK), MBBS (HK)

Department of Ophthalmology, The Hong Kong Sanatorium and Hospital, Hong Kong

\section{Correspondence and reprint requests:}

Dr Alvin KH Kwok, Department of Ophthalmology, 4/F, Li Shu Fan Block, The Hong Kong Sanatorium and Hospital, 2 Village Road, Hong Kong.

Email:alvinkhkwok@netvigator.com

\section{References}

1. PubMed Central $囚$, National Library of Medicine, National Institutes of Health. Information for Publishers: Available at: https://www.ncbi.nlm.nih.gov/pmc/pub/pubinfo/. Accessed 18 May 2020.

2. International Committee of Medical Journal Editors. Recommendations for the Conduct, Reporting, Editing, and
Publication of Scholarly work in Medical Journals. Available at: http://icmje.org/recommendations/. Accessed 18 May 2020.

3. Lau CSL, Fan DSP, Li KKW. Safety and efficacy of atropine treatment for slowing myopia progression in children: a 5-year review. Hong Kong J Ophthalmol 2020;24:11-4. Crossref

4. Wong E, Chan A, Lam C, Lau W, Yam J, Yu C. Retinoblastoma in Hong Kong from 2008 to 2019: looking back and moving forward. Hong Kong J Ophthalmol 2020;24:6-10. Crossref 